\title{
The Derogatory Force and the Offensiveness of Slurs
}

\author{
Chang Liu*
}

Received: 13 November 2020 / Revised: May 32021 / Accepted: 5 June 2021

Abstract: Slurs are both derogatory and offensive, and they are said to exhibit "derogatory force" and "offensiveness." Almost all theories of slurs, except the truth-conditional content theory and the invocational content theory, conflate these two features and use "derogatory force" and "offensiveness" interchangeably. This paper defends and explains the distinction between slurs' derogatory force and offensiveness by fulfilling three goals. First, it distinguishes between slurs' being derogatory and their being offensive with four arguments. For instance, 'Monday', a slur in the Bostonian argot, is used to secretly derogate African Americans without causing offense. Second, this paper points out that many theories of slurs run into problems because they conflate derogatory force with offensiveness. For example, the prohibition theory's account of offensiveness in terms of prohibitions struggles to explain why 'Monday' is derogatory when it is not a prohibited word in English. Third, this paper offers a new explanation of this distinction from the perspective of a speech act theory of slurs; derogatory force is different from offensiveness because they arise from two different kinds of speech acts that slurs are used to perform, i.e., the illocutionary act of derogation and the perlocutionary act of offending. This new explanation avoids the problems faced by other theories.

* Peking University

(D) https://orcid.org/0000-0002-5645-3645

- Department of Philosophy and Religious Studies, Peking University, Beijing, China.

$₫$ ch.liu@live.com

() The Author. Journal compilation (C) The Editorial Board, Organon F.

This article is distributed under the terms of the Creative Commons Attribution-NonCommercial 4.0 International Public License (CC BY-NC 4.0). 
Keywords: Derogation; expressives; offense; pejoratives; slurs; speech acts.

\section{Introduction}

As evaluative terms, slurs are both derogatory and offensive. ${ }^{1}$ On the one hand, slurs are used to derogate a group of people and members of it. For instance, calling a Chinese person ' $\mathrm{ch}^{* *} \mathrm{k}$ ' seems to convey the inferior value of the Chinese. On the other hand, slurs are also used to offend people. For example, calling someone ' $\mathrm{ch}^{* *} \mathrm{k}$ ' in public would outrage many who oppose racism. The goal of theories of slurs is to explain the derogatory force and the offensiveness of slurs.

However, the offensiveness of slurs is commonly confused with the derogatory force of slurs by almost all theorists. Some theories are developed to explain why slurs are "offensive" (Bolinger 2017, Jeshion 2013a, Camp 2013, Anderson and Lepore 2013b). Other theories set out to explain why slurs are "derogatory" (Croom 2011, Richard 2008, Hom 2008, Whiting 2013). Nevertheless, both varieties assume that they are explaining the same phenomenon under different terminologies. Consequently, they use "derogatory force" and "offensiveness" interchangeably. For instance, Jeshion (2013a, 244) defines the "derogatory variation" of utterances as the phenomenon that "utterances of different slurring terms engender different degrees of intensity of offensiveness." Another example is Bolinger's (2017, 439) definition of "offensive autonomy" as the phenomenon that "slurs are offensive even when the speaker does not intend the use to be derogatory". ${ }^{2}$ Hom's (2012) truth-conditional content theory and Davis and McCready's (2020) invocational content theory are the only exceptions that differentiate between being derogatory and being offensive. Nevertheless, I will argue

1 Warning: This paper contains examples of derogatory and offensive language. All examples that mention slurs are covered up with asterisks to minimize unintended effects. I apologize for the potential offense this paper might cause.

2 Another good example comes from Camp (2013, 338), whose theory of slurs claims that "they are offensive because their associated perspectives are negative," but also describes slurs as "expressions that derogate in virtue of membership in a group like race or sex" (Camp 2013, 345). 
that they either fail at explaining derogatory force or fail at explaining offensiveness.

The aim of this paper is to defend and explain the distinction between derogatory force and offensiveness. That is, being derogatory and being offensive are two different properties of slurs. My paper aims at fulfilling three goals, as follows. First, it will present four arguments for this distinction $(\S 2)$. Derogatory force and offensiveness are different because they behave differently in non-slurs, quoted slurs, slurs in argots, and derogatory (or offensive) autonomy. Second, this paper will show how theories of slurs run into problems because they confuse derogatory force with offensiveness (§3). In particular, the conventional implicature theory's explanation of derogatory force does not explain why quoted slurs are offensive. Similarly, the prohibition theory's account of offensiveness can hardly explain why slurs in argots are derogatory. Even if the truth-conditional content theory and invocational content theory draw such a distinction, they nevertheless struggle with either explaining offensiveness or explaining derogatory force. Third, it will explain this distinction with a speech act theory of slurs (§4); slurs are derogatory and offensive because they are used to perform the illocutionary act of derogation and the perlocutionary act of offending, respectively. I will illustrate the advantage of this new explanation in avoiding the problems faced by other theories.

\section{Distinguishing between derogatory force and offensiveness}

In this section, I will present four arguments for the distinction between the derogatory force and the offensiveness of slurs. I will defend two existing arguments (§2.1 difference in non-slurs and $\$ 2.2$ slurs in quotations) and offer two new arguments (§2.3 slurs in argots and $§ 2.4$ offensive and derogatory autonomy).

Before introducing the arguments, I have to clarify my usage of the term "derogatory force" and "offensiveness." First, by "derogatory force," I mean the property of being derogatory. A typical example of being derogatory is making negative remarks about someone. A word is said to possess derogatory force when it is a derogatory word. Similarly, my usage of "offensiveness" refers to the property of being offensive. Good examples of being 
offensive include using the F-word in public or passing gas at a cocktail party. A word instantiates offensiveness when it is an offensive word. For a theory to explain slurs' derogatory force or offensiveness is for it to explain why slurs are derogatory or offensive.

\subsection{Difference in non-slurs}

The first argument for the distinction between derogatory force and offensiveness is that they can come apart in many expressions other than slurs. Although slurs are both derogatory and offensive, Hom and May $(2013,116)$ argue that many expressions can be offensive without being derogatory. Their example is a man's uttering 'You're beautiful.' to a woman passing by. Although the utterance contains only laudatory words, it is still offensive. ${ }^{3}$

A possible objection against Hom and May is that their examples are about the offensiveness of particular utterances (or tokens), not the offensiveness of types of expressions. The type of an expression is offensive when the expression itself is an offensive word, e.g., there is something about the F-word that makes it an offensive word. By contrast, utterances of expressions like 'You're beautiful.' offend people because the way the expressions are used, rather than the expressions themselves, is offensive. This objection insists that what a theory of slurs explains is the offensiveness of the types of slurs, i.e., what makes a word itself an offensive word. Explaining what makes utterances offensive is not the job of a theory of slurs, since any innocent word can be used to offend. Even if Hom and May's examples prove that the offensiveness of utterances is distinct from their derogatory force, their examples do not apply to the offensiveness of the types.

I will defend Hom and May's argument from this objection with examples of offensive but non-derogatory types of expressions. For instance, the British name 'Falklands' is offensive for many Argentinians because they call the disputed island 'Malvinas'. Despite its offensiveness, 'Falklands' is not a derogatory term for the island. Notice that the source of offense is the

3 Moreover, an utterance of a slur can cease to be offensive to an oppressed racial group, once they have internalized racist ideology. Nonetheless, the slur against the oppressed group remains derogatory (Hom and May 2013, 116). 
type, not the particular utterances, of the expression. For example, even a friendly utterance like 'Falkland is a very nice island!' may still be offensive to an Argentinian hearer. This is because he is offended by the name itself, not how it is used in an utterance.

\subsection{Slurs in quotations}

The second argument for the distinction is that the derogatory force of slurs behaves differently than their offensiveness in quotations. Slurs lose their derogatory force when they are mentioned (in pure or mixed quotations) but not directly used. Consider examples such as ' $\mathrm{Ch}^{* *} \mathrm{k}$ ' is a slur for the Chinese.' and 'It is wrong for him to treat them like ' $\mathrm{ch}^{* *} \mathrm{ks}$ '.' Sentences like these are not derogatory against the Chinese. In pure quotations, ' $\mathrm{ch}^{* *} \mathrm{k}$ ' is not used to derogate the Chinese because it is not used at all. In mixed quotations, ' $\mathrm{ch}^{* *} \mathrm{k}$ ' is used to report the derogatory attitude of those who call the Chinese ' $\mathrm{ch}^{* *} \mathrm{ks}$ ', rather than the speaker's attitude.

However, slurs, as Anderson and Lepore (2013a, 36) point out, can remain offensive even if they appear in quotations. For example, Laurie Sheck, a creative writing professor at the New School in New York, mentioned the N-word in her class on I Am Not Your $N^{* * *}$, a documentary on James Baldwin (McWhorter 2019). She asked the students why the title replaced ' $\mathrm{n} * * * \mathrm{er}$ ', the word used in Baldwin's original quote, with ' $\mathrm{n}{ }^{* * *} \mathrm{o}$ '. A white student felt offended and protested her quotation of Baldwin's use of the slur. Even if quoted slurs do not derogate a group, they can still cause offense. $^{4}$

Here is a possible objection against my claim that quoted slurs are nonderogatory: it does not make sense of why quoted slurs can still be prob-

4 There are many explanations of why quoted slurs remain offensive. For Anderson and Lepore (2013), quoted slurs are offensive because using slurs in quotations still violates prohibitions on them. By contrast, Rappaport $(2020,193)$ explains the offensiveness (what he calls "toxicity") of quoted slurs in terms of their neurolinguistic effects; the phonological forms of slurs, even in quotations, can still directly trigger distinct processes in the right hemisphere like curse and taboo words. Despite the different explanations, it has been hardly disputed that quoted slurs can remain offensive.

Organon F 28 (3) 2021: 626-649 
lematic. If quoted slurs were non-derogatory, using them would be unproblematic like saying that "Chinese' is the name for the Chinese.' Nevertheless, non-bigots would be reluctant to even utter slurs in quotations, e.g., " $\mathrm{Ch}^{* *} \mathrm{k}$ ' is a slur for the Chinese.'. There are good reasons to refrain from such utterances; even quoting slurs can have bad consequences.

My response to this objection is to provide an alternative explanation of the problematic nature of quoted slurs. To say that quoted slurs are nonderogatory is not to say that they are unproblematic. Their problematic nature has another source, that is, their offensiveness. We find quoted slurs problematic because they offend many audiences, even if they do not derogate. For instance, someone who has been traumatized by incidents of being called ' $\mathrm{ch}^{* *} \mathrm{k}$ ' can feel offended by merely quoting the slur. This is because hearing the slur itself often suffices to trigger negative experiences. Nonbigots would be reluctant to quote slurs because they would avoid causing such offenses and burdening the victim with traumatic experiences.

\subsection{Slurs in argots}

As for the third argument for the distinction, I will argue that slurs in argots can be derogatory without being offensive. Many slurs in argots are used to secretly derogate a particular group without causing offense. For instance, a police officer was fired for calling Boston Red Sox outfielder Carl Crawford 'Monday'. It turns out that 'Monday', a seemingly innocent word, is a secret slur for African Americans in the Bostonian argot (Zimmer 2012). Similar examples include white waiters' calling black customers 'Canadians', 'cousins', or even 'white people'. In these cases, the point of using argots is to say something derogatory while avoiding offending people. To summarize, slurs can be derogatory without being offensive in argots, and their derogatory force is distinct from their offensiveness.

An objection against my argument is that the so-called "slurs in argots" (e.g., 'Monday') are not really slurs. Therefore, my examples are irrelevant and do not prove the difference between slurs' derogatory force and offensiveness. This objection distinguishes slurs from non-slurs that are used as slurs. On the one hand, this objection insists that for an expression to be a slur, it must be a slur in a natural language like English. For instance, ' $\mathrm{ch}^{* *} \mathrm{k}^{\prime}$ ' is a slur, and it is labeled by English dictionaries as 
"derogatory." ${ }^{5}$ On the other hand, this objection holds that non-slurs can be used as slurs, but this does not make them slurs in a language. Suppose two speakers start to use the word 'water' as a slur for an oppressed group between themselves. Does this fact suddenly make 'water' a slur in English? Should 'water' be banned from public usage like ' $\mathrm{ch}^{* *} \mathrm{k}^{\text {'? }}$ The answer should be "no." This is because being used as a slur by a few speakers does not change the meaning and the use of the word 'water' in English; such usage does not affect the convention of how English speakers use the word in the linguistic community. Likewise, words in argots like 'Monday' are used as slurs but remain non-slurs in English. After all, 'Monday' is not labeled as a slur or even a derogatory expression in dictionaries. One should not be accused of using slurs when one says 'I will see you on Monday.'. In conclusion, my examples do not prove the distinction between slurs' derogatory force and their offensiveness.

My reply to this objection is that there cannot be a clear boundary to exclude slurs in argots (e.g., 'Monday') from what are considered "real slurs" (e.g., ' $\left.\mathrm{ch}^{* *} \mathrm{k}^{\prime}\right)$. Many slurs have evolved gradually from slurs in argots. For instance, 'w*p', an English slur for Italians, originated from 'guappo' (dandy or swaggerer) in the southern Italian dialect (Zimmer 2018). It was introduced by working-class Italian immigrants to New York, where it was misheard as ' $w^{*} \mathrm{p}$ ' by other New Yorkers. Gradually, it was adopted by other English speakers as a slur for Italians. This objection against my argument entails that ' $w^{*} p$ ' started as a non-slur in the New York workers' argot, but it suddenly became a slur in English at a certain point. However, there was never such a magical point. This is because the process for a secret slur in an argot to become a full-blown slur in English is gradual and continuous. As the number of speakers who understand the word grows, a secret slur in the argot of a small group (e.g., New York's immigrant workers) gradually becomes a slur in a dialect of English (e.g., the New York dialect) and eventually becomes a full-blown slur in English. This gradual process also involves a continuous growth of its offensiveness.

5 For the definition in the Oxford English Dictionary, see ' $\mathrm{Ch}^{* *} \mathrm{k}, \mathrm{n} .5$ '. OED Online. December 2020. Oxford University Press. https://www.oed.com/view/Entry $/ 31779$ ?result $=5$ (accessed February 17, 2021). 
Slurs in argots cause no offense or less offense because very few people understand that they are derogatory. As more speakers understand these words, they become more offensive ${ }^{6}$ To summarize, there cannot be a clear boundary to exclude slurs in argots from other slurs in English.

\subsection{Offensive and derogatory autonomy}

Finally, I will give the fourth argument for the distinction, i.e., that derogatory force and offensiveness differ in terms of autonomy. Many theories conflate "derogatory autonomy" with "offensive autonomy", i.e., slurs are said to be derogatory or offensive regardless of the intention of the speaker (Hom 2008, Jeshion 2013a, Bolinger 2017). For instance, the "derogatory force" of slurs is said to be "independent of the attitudes of any of its particular speakers" (Hom 2008, 426). According to Bolinger (2017, 439), "slurs are offensive even when the speaker does not intend the use to be derogatory". These theories often assume that derogatory autonomy is the same thing as offensive autonomy. A good example is the definition from Jeshion (2013a, 233): "slurs are also said to possess derogatory autonomy: the offensiveness of a use of a slurring term is 'autonomous from the beliefs, attitudes, and intentions of individual speakers'".

Nevertheless, I will argue that slurs exhibit offensive autonomy but not derogatory autonomy. That is, slurs are offensive regardless of the speaker's intentions, but slurs' being derogatory is affected by the speaker's intentions. On the one hand, I acknowledge the offensive autonomy of slurs. Slurs can offend hearers even if the speaker does not intend to offend. For instance, saying ' $\mathrm{Ch}^{* *} \mathrm{k}^{\prime}$ ' is a slur for the Chinese.' with the intention to raise awareness of racism can still offend a hearer who finds hearing the slur traumatizing. On the other hand, I deny the derogatory autonomy of slurs. Whether using slurs is derogatory and how derogatory it is (at least sometimes) depend on the intention of the speaker. For example, the $\mathrm{N}$-word can be used by African Americans to express respect, rather than derogatory attitudes, as in 'John Brown is a straight-up n***er.' (Kennedy 2003, 30). Examples like this are often called "the camaraderie use" or "insular

${ }_{6} \quad$ I am grateful to an anonymous reviewer for raising this point. 
reclamation" (Jeshion 2020). ${ }^{7}$ We do not find this utterance of the N-word derogatory because we know that the African American speakers do not intend to derogate themselves. ${ }^{8}$ To summarize, offensiveness is not derogatory force because the former does not depend on the speaker's intention like the latter. ${ }^{9}$

Here is a possible objection against my denial of derogatory autonomy: regardless of the intentions of the speakers, slurs still retain certain derogatory elements in what Jeshion (2020) calls "pride reclamation". ${ }^{10}$ For example, political activists deliberately called themselves 'queer'. In doing so, they showed their unflinching attitude toward the derogatory uses of the bigots. According to Bianchi (2014), these "pride reclamation" uses are nonderogatory because they echo the derogatory uses of the bigots so as to show their disassociation from such derogatory uses. If no derogatory use was echoed, there would be nothing for the speaker to disassociate from.

I have two responses to this objection. First, my rejection of derogatory autonomy does not entail that intentions can always make utterances of slurs non-derogatory. Derogatory autonomy takes derogatory force to be unaffected by intentions. Therefore, it suffices to reject derogatory autonomy if there exist some cases in which utterances of slurs are made nonderogatory by intentions (e.g., the camaraderie uses from (Kennedy 2003, 30)). Second, the example of "pride reclamation" is insufficient for saving derogatory autonomy. This is because derogatory autonomy concerns whether the speaker's utterance of a slur is derogatory; it is not about whether the uses of others "echoed" by the utterance are derogatory. Suppose the activists' utterances of 'queer' echo the uses of the bigots. Even if

7 Slurs can be non-derogatory in other ways. Anderson (2018) points out that the speaker can use slurs to express a neutral or positive attitude in the "referential uses" of slurs. Zeman (2021) proposes that slurs like "tigan" are non-derogatory in their "identificatory uses," in which speakers use these slurs to identify members of their own community.

8 I will explain non-derogatory utterances of slurs with my speech act theory of slurs in $\$ 4.1$.

9 However, there is an exception; institutional derogation does not depend on intentions. I will explain this in $\$ 4.2$.

10 Thanks go to Dan Zeman for pointing to this objection.

Organon F 28 (3) 2021: 626-649 
these utterances echo uses that are derogatory, the activists' utterances themselves remain non-derogatory. Here is an analogy: reporting someone's ridiculous statement does not make the report itself ridiculous. Therefore, pride reclamations do not constitute counterexamples to my rejection of derogatory autonomy.

\section{Challenges for existing theories}

In this section, I will show how conflating derogatory force and offensiveness gives rise to problems for theories of slurs such as the conventional implicature theory (§3.1) and the prohibition theory (§3.2). Although the truth-conditional content theory (§3.3) and the invocational content theory (§3.4) distinguish between being derogatory and being offensive, they still face issues such as slurs in quotations and institutional derogation.

\subsection{The conventional implicature theory}

According to the conventional implicature theory, slurs are derogatory because they carry derogatory conventional implicatures (Whiting 2013, Williamson 2009, Sennet and Copp 2017). For example, what is said by 'Yao is a ch**k.' is the same as 'Yao is a Chinese.'; both are true if and only if Yao is Chinese. Nevertheless, using ' $\mathrm{ch}^{* *} \mathrm{k}^{\prime}$ conventionally implicates derogatory contents such as "a noncognitive attitude of contempt (or scorn or derision or ... )" for the Chinese (Whiting 2013, 265).

However, the conventional implicature theory's account of derogatory force does not apply to offensiveness. In particular, it can hardly explain the offensiveness of slurs in quotations. ${ }^{11}$ As $§ 2.2$ has shown, quoted slurs cease to be derogatory but remain offensive (Anderson and Lepore 2013a, 36). The conventional implicature theory can explain why slurs in quotations are no longer derogatory. This is because conventional implicatures are lost in quotations, e.g., 'But' is a connective.' does not conventionally

11 Anderson and Lepore (2013a) argue against all content-based theories with quoted slurs. Although the conventional implicature theory is not specifically mentioned in their argument, their argument from quoted slurs does challenge this theory. 
implicate a contrast like 'John is rich but kind.' Similarly, " $\mathrm{Ch}^{* *} \mathrm{k}^{\prime}$ ' is a slur for the Chinese.' lacks the conventional implicature that the speaker has a negative attitude toward the Chinese. Unfortunately, this explanation does not apply to offensiveness. If slurs' offensiveness originated from conventional implicatures, " $\mathrm{Ch}^{* *} \mathrm{k}^{\prime}$ ' is a slur for the Chinese.' would be non-offensive. However, the offensiveness of slurs is not lost in quotations like conventional implicatures. There must be something other than conventional implicatures that are responsible for the offensiveness of quoted slurs.

\subsection{The prohibition theory}

The prohibition theory is another theory that struggles with the distinction between derogatory force and offensiveness. According to Anderson and Lepore (2013b), slurs are offensive because they are prohibited words; using slurs violates the prohibition against them. For instance, publicly calling someone ' $\mathrm{ch}^{* *} \mathrm{k}$ ', which is widely forbidden, causes offense because it blatantly violates the prohibition.

However, the prohibition theory's explanation of offensiveness does not apply to derogatory force. It faces two problems. First, it fails to account for the difference in the target of derogatory force and offensiveness. Hom $(2012,379)$ argues that the derogatory force of slurs targets members of a group, whereas their offensiveness targets the audience. For instance, ' $\mathrm{ch}^{* *} \mathrm{k}$ ' is derogatory against the Chinese, but it is not merely offensive to the Chinese; it offends many non-Chinese hearers as well. Hom's distinction presents a problem for the prohibition theory. The prohibition theory can explain why the offensiveness of ' $\mathrm{ch}^{* *} \mathrm{k}$ ' does not merely target the Chinese. This is because using this slur violates the prohibition and therefore causes offense to the hearers who uphold this prohibition. Unfortunately, this is not applicable to its derogatory force; slurs are not derogatory against those who prohibit the slurs. A white hearer can be offended by someone's usage of ' $\mathrm{ch}^{* *} \mathrm{k}$ ', because he is against using racial slurs. Nevertheless, this does not make ' $\mathrm{ch}^{* *} \mathrm{k}$ ' a derogatory word against white people. Therefore, there must be something other than violating prohibition that explains why derogatory force is more limited in its targets.

Second, the prohibition theory can hardly explain why slurs in argots can be derogatory without being offensive. The prohibition theory does offer 
a plausible account of why slurs in argots are not offensive. This is because there is no existing prohibition on those words. In fact, the point of speaking in argots is to bypass existing prohibitions. For example, calling someone 'Monday' often does not cause offense because 'Monday' is not a prohibited word. Nevertheless, this explanation does not apply to the derogatory force. Slurs like 'Monday' remain derogatory despite being non-offensive and not prohibited. If it is derogatory without being prohibited, derogatory force must have sources other than prohibition.

\subsection{The truth-conditional content theory}

Although Hom's truth-conditional content theory offers explanations for both the offensiveness and the derogatory force of slurs, his theory nonetheless struggles with explaining offensiveness.

Hom explains slurs' derogatory force in terms of their derogatory truthconditional contents. For instance, ' $\mathrm{ch}^{* *} \mathrm{k}$ ' means "ought to be subject to higher college admissions standards, and ought to be subject to exclusion ... , because of being slanty-eyed, and devious, and good-at-laundering ... , all because of being Chinese" (Hom 2012, 394). Consequently, saying that "Yao is a $\mathrm{ch}^{* *} \mathrm{k}$.' is derogatory because it attributes derogatory properties in the content of slurs to the target. Unfortunately, it follows that sentences like 'There are no $\mathrm{ch}^{* *} \mathrm{ks}$ in the building.' cannot be derogatory because it does not attribute the negative content to anyone. This seems to entail the counterintuitive claim that nothing is wrong with such a negative existential. To address this problem, Hom distinguishes between derogatory force and offensiveness: 'There are no $\mathrm{ch}^{* *} \mathrm{ks}$ in the building.' is non-derogatory but still offensive.

Hom $(2012,402)$ explains the offensiveness of slurs in terms of conversational implicatures, instead of truth-conditional contents. 'There are no $\mathrm{ch}^{* *} \mathrm{ks}$ in the building.' is offensive because it carries offensive conversational implicatures. A speaker would not use ' $\mathrm{ch}^{* *} \mathrm{k}$ ' unless he was committed to the existence of ' $\mathrm{ch}^{* *} \mathrm{ks}$ ', i.e., people who satisfy the negative properties. Consequently, 'There are no $\mathrm{ch}^{* *} \mathrm{ks}$ in the building.' conversationally implicates that the speaker is committed to the existence of people who should be subject to discrimination because of being slanty-eyed, devious ... and being Chinese, etc. 
Nevertheless, Hom's explanation of offensiveness still faces problems. First, Jeshion $(2013 \mathrm{~b}, 317)$ argues that explaining offensiveness with conversational implicature is problematic in terms of cancellability. Conversational implicatures are cancellable (Grice 1989, 39), but the offensiveness of slurs is not cancellable. For instance, saying 'There are no $\mathrm{ch}^{* *} \mathrm{ks}$ in the building.' does not cease to be offensive once the speaker clarifies that 'Don't get me wrong. I don't think there are people who should be discriminated against for being Chinese.'. However, if the offensiveness of ' $\mathrm{ch}^{* *} \mathrm{k}$ ' came from conversational implicature, it would be cancellable.

Second, I will argue that Hom's explanation of offensiveness struggles with slurs in quotations. According to Hom (2012, 402), a key premise in the inferences to slurs' offensive conversational implicatures is that a speaker usually does not use a word unless he is committed to the nonempty extension of the word. However, this premise does not work for quotations. This is because speakers do not commit to the non-empty extension of a word when they quote the word. This is often why quotations can be used to deny the existence of something. For instance, 'Liberals are obsessed by the so-called 'systematic racism'.' and 'He claims that 'systematic racism' is pervasive.' does not commit the speaker to the existence of systematic racism. Quotations at most report the third party's commitment to the non-empty extension but not the speaker's commitment. Likewise, " $\mathrm{Ch}{ }^{* *} \mathrm{k}$ ' is a slur for the Chinese.' and 'He says that Yao is a ' $\mathrm{ch}^{* *} \mathrm{k}$ '.' do not commit the speaker to the existence of ' $\mathrm{ch}^{* *} \mathrm{ks}$ '. Nevertheless, slurs remain offensive even in quotations. If so, their offensiveness cannot come from the kind of inference to conversational implicatures that Hom describes.

\subsection{The invocational content theory}

Davis and McCready's (2020) "invocational theory" takes slurs to be mixed expressives, the semantic contents of which consist of two components. First, a slur has an at-issue semantic content, which is simply the property of being a member of a group. Second, it has an expressive content (also called "invocational content"), which invokes "a complex of sociohistorical facts, attitudes, and prejudices about the group" (Davis and McCready 2020, 65). To invoke such a complex of things is to impose them to the context, i.e., updating the context to making them salient in it. Davis 
and McCready's theory follows Potts's (2005, 2007) framework in treating expressivist contents as a kind of conventional implicature, which is analyzed as an extra content in addition to the at-issue semantic content.

Davis and McCready's theory also differentiates between derogatory force and offensiveness. It gives a semantic explanation of the offensiveness of slurs. Slurs are offensive regardless of the speaker's intention because no matter how they are used, the invoked contents of slurs are offensive by themselves. ${ }^{12}$ However, Davis and McCready realize that this explanation

12 It is unclear how Davis and McCready's theory, which treats invocational contents with Potts's framework of conventional implicatures, can explain the offensiveness of slurs in quotations. On the one hand, slurs remain offensive even if they are in quotations. However, it is not clear whether the conventional implicatures or invocational contents always project through the scope of quotations. Potts's (2005, 2007) work do not offer an analysis of conventional implicatures in quotations. Without giving justifications, Davis and McCready's (2020, 73) account of offensiveness assumes that conventional implicatures or invocational contents always project through quotations; "the very utterance of a slur will result in an invocation of its expressively encoded content ... no amount of embedding will help to diffuse the offensiveness that results."

However, their assumption about projection applies to mixed quotations but not pure quotations. Expressions in mixed quotations are both used and mentioned (e.g., 'John said that slurs are 'offensive'.'), whereas expressions in pure quotations are merely mentioned but not used (e.g., 'The word 'offensive' has nine letters.') (Davidson 1979). Expressions in mixed quotations can contribute their conventional implicatures to the sentence because they are still used in a way (e.g., the contrast between being rich and being kind is reported in 'John is said to be rich 'but' kind.'). Davis and McCready's assumption seems to work because they only consider slurs in mixed quotations, e.g., 'It's because he thinks of you as a S.', where S is a quoted slur (Davis and McCready 2020, 71). However, expressions in pure quotations are not used at all, and they do not seem to contribute their conventional implicatures to sentences (e.g., the conventionally implicated contrast is not reported in 'The word 'but' consists of three letters.'). It is unclear how Davis and McCready's "invocational contents," based on Potts's logic of conventional implicatures, can explain the offensiveness of pure quotations like ' $\mathrm{Ch}^{* *} \mathrm{k}$ ' consists of five letters.' It would be surprising and ad hoc if their theory made an exception for slurs. Why would the conventional implicatures of slurs project through pure quotations, while other conventional implicatures could not? 
of offensiveness does not apply to slurs' derogatory force, which to some extent depends on the speaker's intention. Consequently, their invocational content theory gives a pragmatic explanation of the derogatory force, i.e., "derogation is derived through reasoning about speaker attitudes" (Davis and McCready 2020, 69).

However, I argue that the invocational content theory struggles with slurs' derogatory force, especially in cases of institutional derogation. Davis and McCready explain non-derogatory uses of slurs in terms of the speaker's intentions; some utterances of slurs are not derogatory because hearers infer from the utterances that the speaker does not intend to endorse the offensive contents invoked by slurs. I agree with them that the speaker's intentions play a crucial role, but I do not think appealing to intentions gives the whole picture. There are cases of institutional derogation, where slurs remain derogatory despite the speaker's lack of bad intentions. Imagine that the spokesperson of a racist government calls the Chinese ' $\mathrm{ch}^{* *} \mathrm{ks}$ ' in an official statement. Suppose we know the spokesperson is Chinese and has no intention to endorse anti-Chinese racism. Nevertheless, the slur remains derogatory against the Chinese, no matter what the speaker personally intends. This is because the spokesperson speaks on behalf of a state, not just himself. In general, slurs are not made non-derogatory by the lack of bad intentions, when they are used with institutional power (e.g., by government officials, college professors, and corporate managers).

\section{Explanation from a speech act theory of slurs}

In this section, I will explain the distinction between derogatory force and offensiveness with a speech act theory of slurs (§4.1). I will illustrate the advantage of this explanation in avoiding the problems faced by other theories $(\S 4.2)$.

\subsection{The speech act theory of slurs}

The speech act theory of slurs explains derogatory force and offensiveness in terms of the speech acts that slurs are used to perform. It was developed in earlier works of mine to capture this basic idea: the use of slurs 
is not merely to express contents but to do something against their targets (Liu 2019a, 2021). ${ }^{13}$ In particular, slurs are derogatory words because they are used to perform the act of derogation, and they are offensive words because they are used to offend people. The earlier version of this theory conflated derogatory force with offensiveness like other theories. However, this paper will present a modified version, which distinguishes between derogatory force and offensiveness with different kinds of speech acts.

Slurs' being derogatory is not the same as their being offensive because to derogate is a different kind of speech act from to offend. Derogation is an illocutionary act, i.e., acts of doing something in saying something (e.g., promising, apologizing, asserting). By contrast, offending belongs to the category of perlocutionary acts, i.e., acts of producing certain effects by saying something (e.g., convincing, scaring, persuading).

The revised version of the speech act theory of slurs can be summarized as the conjunction of three theses:

The Speech Act Theory of Slurs:

(1) One of the uses of slurs is to derogate their targets because they are illocutionary force indicators of the illocutionary acts of derogation.

(2) The other use of slurs is to offend the audiences because of their perlocutionary effects of triggering stereotypical inferences to negative properties.

(3) Slurs are propositional indicators that have the same truth-conditional contributions as their neutral counterparts.

Thesis 1 explains the derogatory force of slurs. Why is a slur like ' $\mathrm{ch}^{* *} \mathrm{k}$ ' a derogatory word? According to the speech act theory of slurs, one of the two uses of slurs is to derogate their target groups. In other words, they are illocutionary force indicators of derogation. For instance, uttering 'Yao is a $\mathrm{ch}^{* *} \mathrm{k}$.' is derogatory against the Chinese, because ' $\mathrm{ch}^{* *} \mathrm{k}$ ' provides the illocutionary force of derogation against the Chinese. That is, this slur makes it explicit that 'Yao is a $\mathrm{ch}^{* *} \mathrm{k}$.' should be taken as an illocutionary act of derogating the Chinese, which consists of the illocutionary force of derogation and the content, i.e., Chinese Derogation is a declarative illocutionary

13 For more arguments for this speech act theory and its advantage over earlier speech act approaches, see (Liu 2021). 
act, the point of which is to enforce a norm against the target. For instance, to derogate the Chinese by calling them ' $\mathrm{ch}^{* *} \mathrm{k}^{\prime}$ is to enforce racist norms in which the Chinese deserve to be treated with violence and are deprived of their dignity, etc.

Here is a quick caveat on the function of illocutionary force indicators. An illocutionary act usually consists of an illocutionary force and a content, e.g., promising that I will come to the party has the force of promising and the content that I will come to the party. The force and the contents can come from what is called "illocutionary force indicators" (e.g., expressions like 'I promise', 'I apologize', 'hello' etc.) and what is called "propositional indicators" (e.g., expressions like 'that I will come to the party') respectively (Searle 1969, 30). Force indicators make the illocutionary force of an utterance explicit (e.g., saying that 'I promise ...' makes it explicit that the utterance should be taken as a promise, rather than greetings or condolences) (Searle 1996, 30). Austin $(1962,70)$ has an analogy of making the illocutionary force explicit: raising a hat makes it explicit that the earlier act of bowing should be taken as an act of paying respect, rather than an act of observing flowers on the ground.

Thesis 2 is added to this revised version to explain the offensiveness of slurs. Why is a slur like ' $\mathrm{ch}^{* *} \mathrm{k}$ ' offensive? The speech act theory holds that slurs are used to perform the perlocutionary act of offending the hearers. This is because slurs produce the perlocutionary effects of triggering stereotypical inferences to negative properties. Studies find that linguistic expressions are associated with stereotypical properties that come to mind when the expressions are heard (Hare, et al. 2009, Ferretti, McRae and Hatherell 2001, Harmon-Vukić, et al. 2009). Such stereotypes trigger automatic inferences, e.g., inferring that someone is female from her being called a 'secretary' (Atlas and Levinson 1981). Similarly, hearing ' $\mathrm{ch}^{* *} \mathrm{k}^{\prime}$ causes offense because it automatically triggers the stereotypical inferences to offensive properties associated with the Chinese, such as being slanty-eyed, devious, etc.

Thesis 3 addresses the descriptive component of slurs. As evaluative terms, slurs also make truth-conditional contributions; they are not like purely evaluative or expressive terms such as 'damn'. In other words, slurs are propositional indicators that contribute to the truth-condition. In 
particular, a slur like ' $\mathrm{ch}^{* *} \mathrm{k}$ ' has the same truth-conditional contribution as its neutral counterpart, e.g., 'Chinese'. For instance, 'Yao is a $\mathrm{ch}^{* *}$ k.' is true if and only if 'Yao is a Chinese.' is true.

The speech act theory of slurs, by distinguishing between the two kinds of speech acts, explains the many differences between derogatory force and offensiveness introduced by the arguments in $§ 2$. First, the speech act theory can explain why derogatory force and offensiveness can come apart in non-slurs. This is because an utterance can be an illocutionary act of derogation without being a perlocutionary act of offending someone, and vice versa. Consequently, a word can be a force indicator of derogation without producing the perlocutionary effects that cause offense, and vice versa. For instance, 'Falkland' is an offensive word to Argentinians because it triggers stereotypical inferences to properties such as "belonging to the UK", "military invasion", "Argentinian defeat" etc. Nonetheless, it is not a derogatory word because it is not a force indicator used to derogate the island. Likewise, an expression can be derogatory without being offensive when it is an illocutionary force indicator of derogation without having perlocutionary effects of triggering stereotypical inferences to negative properties.

Second, my theory explains the difference between derogatory force and offensiveness in autonomy, i.e., why being derogatory depends on the speaker's intention but being offensive does not. This is because the illocutionary act of derogation can be made infelicitous or unsuccessful by the speaker's intention. ${ }^{14}$ For instance, when an African American speaker utters 'John Brown is a straight-up $\mathrm{n}^{* * *}$ er.', this utterance is not an act of derogating African Americans. This is because successful derogation requires that the speaker must intend to impose a norm against the target. Moreover, we know the African American speaker is very unlikely to impose a racist norm against his own community in using the $\mathrm{N}$-word. Unlike the derogatory force, offensiveness is autonomous or independent from the speaker's intention. This is because whether a slur successfully produces its perlocutionary effects is determined by the hearers, not the speaker. For instance, a hearer is offended by ' $\mathrm{ch}^{* *} \mathrm{k}$ ' so long as it triggers stereotypical inferences in the hearer, even if the speaker does not intend to offend.

14 For a more detailed analysis of non-derogatory utterances of slurs, see (Liu 2019b, 2021). For the exception of institutional derogation, see the following section. 
In addition, my theory also explains why slurs in quotations remain offensive and why slurs in argots can be non-offensive. I will give detailed explanations in the following section since these two issues challenge other theories.

\subsection{Advantages over other theories}

The advantage of my explanation of derogatory force and offensiveness is that it avoids the problems faced by other theories.

In comparison to the conventional implicature theory, the speech act theory of slurs does a better job of explaining why quoted slurs, despite being non-derogatory, can be offensive. Slurs in quotations are non-derogatory because illocutionary force indicators in quotations cannot be used to perform speech acts (e.g., saying that "I promise' is an illocutionary force indicator.' does not make a promise). Likewise, " $\mathrm{Ch}^{* *} \mathrm{k}$ ' is a slur for the Chinese.' does not have the use to derogate the Chinese. However, quoted slurs remain offensive because quoted words can still trigger stereotypical inference in the hearers. Upon hearing ' $\mathrm{Ch}^{* *} \mathrm{k}$ ' is a slur for the Chinese.', the slur automatically triggers stereotypical inferences to negative properties such as being slanty-eyed and devious.

As for the prohibition theory, the speech act theory enjoys two advantages over it. First, my theory explains why the derogatory force and the offensiveness of slurs have different targets. For instance, ' $\mathrm{ch}^{* *} \mathrm{k}$ ' is derogatory against the Chinese because it is an illocutionary force indicator of derogation against the Chinese. However, ' $\mathrm{ch}^{* *} \mathrm{k}$ ' is not merely offensive to the Chinese. This is because slurs also trigger stereotypical inferences to negative properties in non-Chinese hearers. Second, my theory performs better at explaining the offensiveness of slurs in argots. Slurs like 'Monday' can be derogatory without being offensive. This is because it is an illocutionary force indicator of derogation against the African Americans in the Bostonian argot. Nevertheless, it is not offensive because it does not trigger stereotypical inferences in the hearers. For the hearers who are not familiar with the argot, 'Monday' is not associated with the stereotypical properties of African Americans.

Although Hom's truth-conditional content theory also differentiates between derogatory force and offensiveness, my theory performs better than 
it in two ways. First, it explains the non-cancellability of slurs' offensiveness. One cannot explicitly cancel the offensiveness of 'There are no $\mathrm{ch}^{* *} \mathrm{ks}$ the building.' with 'Don't get me wrong. I don't think there are people who should be discriminated against for being Chinese.' This is because offensiveness arises from the perlocutionary effects of stereotypical inferences. Such inferences are automatic and involuntary. Therefore, it cannot be canceled by opting out of the cooperative principle. Second, my theory has no problem in explaining the offensiveness of quoted slurs, as I have just described.

Finally, my theory differs from Davis and McCready's invocational content theory in two aspects. To be illocutionary force indicators is not the same as expressing "invocational contents". First, these two theories disagree over the effects of the slurs. For the invocational content theory, the primary effects of the invocational content are linguistic; their job is to change the contexts, e.g., making certain contents salient. Contextual changes affect the interpretations of context-sensitive expressions and the directions of discourses. By contrast, the speech act theory does not take the primary effects of slurs to be merely linguistic; their use is to perform the acts of derogation that change the normative status of the target (e.g., rights, obligations, what are allowed and forbidden to do), not just how we talk about them. For instance, the slur ' $\mathrm{ch}^{* *} \mathrm{k}$ ' is harmful because it enforces anti-Chinese norms that deny the rights of the Chinese, license violence against them, and deprive them of dignity.

Second, these two theories have different views on the sources of derogatory force. The invocational content theory explains the derogatory force of slurs in terms of inferences to the speaker's intentions. It follows that slurs are not derogatory when we infer that the speaker has no bad intentions. While the speech act theory allows such inferences to affect the derogatory force of slurs, it does not take these inferences to be the source of derogatory force. Instead, slurs are derogatory because they are used to perform the speech act of derogation, which can be made unsuccessful by the lack of derogatory intentions in certain cases.

By limiting the role of the speaker's intention, the speech act theory of slurs is immune to the problem of institutional derogation faced by the invocational content theory. Like many other illocutionary acts (e.g., 
personal apologies and official apologies), derogation can be distinguished into personal derogation (e.g., making negative remarks to my friends at a party) and institutional derogation (e.g., issuing an official condemnation as the president). Personal derogation does not require institutional power to perform, but its success requires that the speaker intends to impose a norm against the target. By contrast, the successful performance of institutional derogation has requirements on the role of the speaker (e.g., the speaker must occupy offices such as being the president or the spokesperson to derogate on behalf of an institution), but not her personal intentions. In conclusion, my speech act theory holds that slurs, when used with institutional power, can be derogatory regardless of the speaker's intention. This is because the successful performance of institutional derogation, unlike personal derogation, does not depend on intentions.

\section{Conclusion}

In this paper, I have achieved three goals. First, I have presented four arguments for the distinction between slurs' derogatory force and offensiveness. For instance, being derogatory is not the same as being offensive because slurs in argots, e.g., 'Monday', are used to derogate their targets without causing offense. Second, I have argued that failing to draw such a distinction has given rise to problems for theories of slurs. The prohibition theory, for example, cannot explain the derogatory force in terms of the prohibition. This is because slurs in argots (e.g., 'Monday') are used to derogate their targets even if there is no prohibition on them. Third, I have offered a new explanation of this distinction with a speech act theory of slurs, which distinguishes between the two uses of slurs, i.e., performing the illocutionary act of derogation and performing the perlocutionary act of offending. The advantage of this new explanation is that it avoids the difficulties of other theories, such as slurs in quotations and slurs in argots.

These considerations, I hope, justify the distinction between slurs' derogatory force and offensiveness. There is more than one way for slurs, as well as other terms, to be expressive. 


\section{References}

Anderson, Luvell. 2018. "Calling, Addressing, and Appropriation." In Bad Words, edited by David Sosa, 6-26. Oxford: Oxford University Press.

https://doi.org/10.1093/oso/9780198758655.001.0001

Anderson, Luvell, and Ernie Lepore. 2013a. "Slurring Words." Noûs 47 (1): 25-48. https://doi.org/10.1111/j.1468-0068.2010.00820.x

Anderson, Luvell, and Ernie Lepore. 2013b. "What Did You Call Me? Slurs as Prohibited Words." Analytic Philosophy 54 (3): 350-63.

https://doi.org/10.1111/phib.12023

Atlas, Jay David, and Stephen C. Levinson. 1981. "It-clefts, Informativeness and Logical Form: Radical Pragmatics (Revised Standard Version)." In Radical Pragmatics, edited by Peter Cole, 1-62. New York: Academic Press.

Austin, J. L. 1962. How to Do Things with Words. Clarendon Press.

Bianchi, Claudia. 2014. "Slurs and Appropriation: An Echoic Account." Journal of Pragmatics 66: 35-44. https://doi.org/10.1016/j.pragma.2014.02.009

Bolinger, Renée Jorgensen. 2017. "The Pragmatics of Slurs." Nô̂s 51 (3): 439-62. https://doi.org/10.1111/nous.12090

Camp, Elisabeth. 2013. "Slurring Perspectives." Analytic Philosophy 54 (3): 33049. https://doi.org/10.1111/phib.12022

Croom, Adam M. 2011. "Slurs." Language Sciences 33 (3): 343-58. https://doi.org/10.1016/j.langsci.2010.11.005

Davidson, Donald. 1979. "Quotation." In Inquiries into Truth and Interpretation, 79-92. Oxford: Oxford University Press.

Davis, Christopher, and Elin McCready. 2020. "The Instability of Slurs." Grazer Philosophische Studien 97 (1): 63-85. https://doi.org/10.1163/1875673509701005

Ferretti, Todd R., Ken McRae, and Andrea Hatherell. 2001. "Integrating Verbs, Situation Schemas, and Thematic Role Concepts." Journal of Memory and Language 44 (4): 516-47. https://doi.org/10.1006/jmla.2000.2728

Grice, Paul. 1989. Studies in the Way of Words. Harvard University Press.

Hare, Mary, Michael Jones, Caroline Thomson, Sarah Kelly, and Ken McRae. 2009. "Activating Event Knowledge." Cognition 111 (2): 151-67. https://doi.org/10.1016/j.cognition.2009.01.009

Harmon-Vukić, Mary, Sabine Guéraud, Karla A. Lassonde, and Edward J.

O'Brien. 2009. "The Activation and Instantiation of Instrumental Inferences." Discourse Processes 46 (5): 467-90.

https://doi.org/10.1080/01638530902959661

Hom, Christopher. 2012. "A Puzzle About Pejoratives." Philosophical Studies 159 (3): 383-405. https://doi.org/10.1007/s11098-011-9749-7 
Hom, Christopher. 2008. "The Semantics of Racial Epithets." Journal of Philosophy 105 (8): 416-40. https://doi.org/10.5840/jphil2008105834

Hom, Christopher, and Robert May. 2013. "Moral and Semantic Innocence." Analytic Philosophy 54 (3): 293-313. https://doi.org/10.1111/phib.12020

Jeshion, Robin. 2020. "Pride and Prejudiced." Grazer Philosophische Studien 97 (1): 106-37. https://doi.org/10.1163/18756735-09701007

Jeshion, Robin. 2013a. "Expressivism and the Offensiveness of Slurs." Philosophical Perspectives 27 (1): 231-59. https://doi.org/10.1111/phpe.12027

Jeshion, Robin. 2013b. "Slurs and Stereotypes." Analytic Philosophy 54 (3): 31429. https://doi.org/10.1111/phib.12021

Kennedy, Randall. 2003. Nigger: The Strange Career of a Troublesome Word. New York: Vintage Books.

Liu, Chang. 2021. "Slurs as Illocutionary Force Indicators." Philosophia 49 (3): 1051-65. https://doi.org/10.1007/s11406-020-00289-0

Liu, Chang. 2019a. Derogatory Words and Speech Acts: An Illocutionary Force Indicator Theory of Slurs. PhD dissertation: The University of Western Ontario.

Liu, Chang. 2019b. "Slurs and the Type-Token Distinction of Their Derogatory Force." Rivista Italiana di Filosofia del Linguaggio 13 (2): 63-72. https://doi.org/10.4396/12201902

McWhorter, John. 2019. "The Idea That Whites Can't Refer to the N-Word." The Atlantic. August 27. Accessed November 12, 2020.

https://www.theatlantic.com/ideas/archive/2019/08/whites-refer-to-the-nword/596872/

Potts, Christopher. 2007. "The Expressive Dimension." Theoretical Linguistics 33 (2): 165-98. https://doi.org/10.1515/TL.2007.011

Potts, Christopher. 2005. The Logic of Conventional Implicatures. Oxford: Oxford University Press.

Rappaport, Jesse. 2020. "Slurs and Toxicity." Grazer Philosophische Studien 97 (1): 177-202. https://doi.org/10.1163/18756735-09701010

Richard, Mark. 2008. When Truth Gives Out. Oxford: Oxford University Press.

Searle, John R. 1996. "What Is a Speech Act?" In The Philosophy of Language (third edition), edited by A. P. Martinich, 130-40. Oxford University Press.

Searle, John R. 1969. Speech Acts: An Essay in the Philosophy of Language. Cambridge University Press.

Sennet, Adam, and David Copp. 2017. "Pejoratives and Ways of Thinking." Analytic Philosophy 58 (3): 248-271. https://doi.org/10.1111/phib.12100

Whiting, Daniel. 2013. "It's Not What You Said, It's the Way You Said It: Slurs and Conventional Implicatures." Analytic Philosophy 54 (3): 364-77. https://doi.org/10.1111/phib.12024 
Williamson, Timothy. 2009. "Reference, Inference, and the Semantics of Pejoratives." In The Philosophy of David Kaplan, edited by Joseph Almog, and Paolo Leonardi, 137-59. Oxford University Press.

Zeman, Dan. 2021. "A Rich-lexicon Theory of Slurs and Their Uses." Inquiry. https://doi.org/10.1080/0020174X.2021.1903552

Zimmer, Ben. 2018. "Wop' Doesn't Mean What Andrew Cuomo Thinks It

Means." The Atlantic. April 23, 2018. Accessed November 9, 2020.

https://www.theatlantic.com/politics/archive/2018/04/wop-doesnt-mean-whatandrew-cuomo-thinks-it-means/558659/

Zimmer, Ben. 2012. "How Did 'Monday' Become a Racist Slur?" Boston Globe. July 29, 2012. Accessed November 3, 2020.

https://www.bostonglobe.com/ideas/2012/07/28/how-did-monday-becomeracist-slur-how-did-monday-become-racist-

slur/Mf4fQEVcXabGKHFaDMZ4NO/story.html 